\title{
Vaihtuvasta magnesiumista Lounais-Suomen viljellyissä savimaissa
}

\author{
Kalevi Virri ja Jouko Sippola \\ Maatalouden tutkimuskeskus, Maantutkimuslaitos, 01300 Vantaa 30
}

\section{Exchangeable magnesium in south-west Finnish cultivated clay soils}

KAlevi VirRi and Jouko Sippola

Agricultural Research Centre, Institute of Soil Science, 01300 Vantaa 30, Finland

\begin{abstract}
Clay soils sampled from south-west Finnish clay area up to the adjoining silty soil area contained in neutral ammonium acetate exchangeable magnesium from 3.2 to $9.0 \mathrm{me} / 100 \mathrm{~g}$ soil. The ratio of the equivalent amounts of calcium to magnesium was in the surface soil $2.2-2.6$ and in deeper layers $1.1-1.5$. The corresponding ratios of magnesium to potassium were $6-10$ and $17-23$. For plant husbandry the content of exchangeable magnesium in the studied clay soils appears to be adequate and in relation to other cations plentiful.
\end{abstract}

\section{Johdanto}

Maan vaihtokapasiteettiin vaikuttavat sekä saveksen että eloperäisen aineen määrä ja laatu. Maahan vaihtuviksi pidättyneiden ionien lajit ja määräsuhteet riippuvat mm. alkuperämineraaleista ja rapautumisen kulusta. Suomen maalajeissa ovat magnesiumin lähteinä lähinnä biotiitti, kloriitti ja vermikuliitti (SIPPOLA 1974). Mereen sedimentoituneissa savissa osa pidättyneistä ioneista on peräisin merivedestä. Magnesiumia tulee viljelysmaihin myös lannoitteissa ja kalkitusaineissa ja täten voidaan vaihtuvien kationien määräsuhteisiin vaikuttaa.

Tämän tutkimuksen tarkoituksena on vertailla kahden savimaistaan tunnetun alueen viljelysmaiden vaihtuvan magnesiumin määriä sekä niiden suhdetta vaihtuvaan kalsiumiin ja kaliumiin.

\section{Aineisto ja menetelmät}

Tutkimusaineisto, joka on esitetty taulukossa 1, kerättiin maaperäkartoituksen yhteydessä yhteensä 48:sta savimaan profiilista Lohjan ja Vammalan alueilta (VIRRI 1971 ja 1973). Vaihtuvat kationit uutettiin neutraalilla $1 \mathrm{~N}$ 
Taulukko 1. Lohjan ja Vammalan alueiden näytteiden keskimääräiset saveksen, hienon hiesun ja orgaanisen hiilen pitoisuudet sekä pH-luvut standardipoikkeamineen.

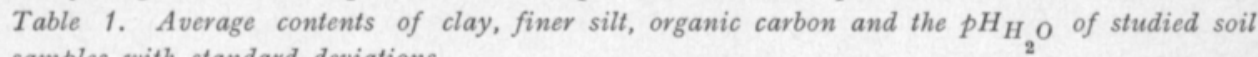
samples with standard deviations.

\begin{tabular}{|c|c|c|c|c|c|}
\hline $\begin{array}{l}\text { Alue } \\
\text { Area }\end{array}$ & $\begin{array}{l}\text { Näyteluku } \\
\text { Number of } \\
\text { samples }\end{array}$ & $\begin{array}{c}\text { Savesta } \\
\text { Clay } \\
<2 \mu \%\end{array}$ & $\begin{array}{c}\text { Hienoa hiesua } \\
\text { Finer silt } \\
2-6 \mu \%\end{array}$ & $\begin{array}{c}\text { Org. C } \\
\%\end{array}$ & $\mathrm{pH}_{\mathrm{H}_{2} \mathrm{O}}$ \\
\hline $\begin{array}{l}\text { Muokkauskerros } \\
\text { Plough layer } 0-20 \mathrm{~cm}\end{array}$ & & & & . & \\
\hline $\begin{array}{l}\text { Lohja } \ldots a . \ldots \ldots \ldots \ldots \ldots \ldots \ldots \\
\text { Vammala } \ldots \ldots \ldots \ldots \ldots \ldots \ldots \ldots\end{array}$ & $\begin{array}{r}27 \\
7\end{array}$ & $\begin{array}{l}50 \pm 4 \\
38 \pm 3\end{array}$ & $\begin{array}{l}18 \pm 2 \\
28 \pm 5\end{array}$ & $\begin{array}{l}3.9 \pm 0.3 \\
3.5 \pm 0.4\end{array}$ & $\begin{array}{l}5.7 \pm 0.16 \\
5.3 \pm 0.13\end{array}$ \\
\hline $\begin{array}{l}\text { Jankko } \\
\text { Subsurface } 20-40 \mathrm{~cm}\end{array}$ & & & & & \\
\hline 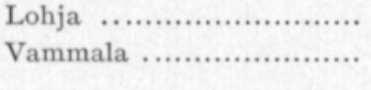 & $\begin{array}{l}35 \\
11\end{array}$ & $\begin{array}{l}52 \pm 5 \\
43 \pm 8\end{array}$ & $\begin{array}{l}17 \pm 2 \\
28 \pm 3\end{array}$ & $\begin{array}{l}1.3 \pm 0.3 \\
0.8 \pm 0.4\end{array}$ & $\begin{array}{l}5.9 \pm 0.17 \\
5.8 \pm 0.27\end{array}$ \\
\hline $\begin{array}{l}\text { Pohjamaa } \\
\text { Subsoil } 40-60 \mathrm{~cm}\end{array}$ & & ' & & $x$ & \\
\hline $\begin{array}{l}\text { Lohja } . . . \ldots \ldots \ldots \ldots \ldots \ldots \ldots \\
\text { Vammala } . . . \ldots \ldots \ldots \ldots \ldots \ldots \ldots\end{array}$ & $\begin{array}{l}36 \\
13\end{array}$ & $\begin{array}{l}56 \pm 6 \\
48 \pm 6\end{array}$ & $\begin{array}{l}17 \pm 2 \\
25 \pm 4\end{array}$ & $\begin{array}{l}0.6 \pm 0.1 \\
0.5 \pm 0.1\end{array}$ & $\begin{array}{l}6.1 \pm 0.17 \\
6.0 \pm 0.32\end{array}$ \\
\hline
\end{tabular}

ammoniumasetaatilla (Schollenberger ja Simon 1945). Kalium määritettiin liekkifotometrisesti, kalsium ja magnesium versenaattimenetelmällä. Vaihtuva vety määritettiin BRownin (1943) menetelmällä. Kokonaisvaihtokapasiteetti saatiin yhteenlaskemalla ottaen myös vaihtuva natrium huomioon.

Maan pH mitattiin vesilietteestä (1:2.5). Lajitekoostumus analysoitiin seulonnoilla ja pipettimenetelmällä esikäsittelyinä $\mathrm{H}_{2} \mathrm{O}_{2^{-}}, \mathrm{HCl}-$ ja $\mathrm{Na}_{2} \mathrm{P}_{2} \mathrm{O}_{7^{-}}$ käsittelyt. Orgaaninen hiili määritettiin kolorimetrisellä bikromaattimärkäpoltolla. Tuloksia käsiteltiin IBM 1130 tietojenkäsittelykoneella korrelaatioja regressio-ohjelmilla olettaen lukuparvien jakautuvan normaalisti.

\section{Tulokset ja tulosten tarkastelu}

\section{Vaihtuva magnesium}

Vaihtuvaa magnesiumia on Lohjan seudun näytteissä keskimäärin 4.9-9.0 milliekvivalenttia sadassa grammassa ilmakuivaa maata (taulukko 2). Alin keskiarvo saatiin muokkauskerroksesta, korkein pohjamaasta. Korkeimmat yksittäiset tulokset, $15-20$ me, olivat aitosaven pohjamaassa. Vammalan seudun näytteissä on vaihtuvaa magnesiumia vastaavasti $3.2-7.7$ me. Korkeimmat yksittäiset tulokset, 10-12 me, saatiin pohjamaanäytteistä. Alhaisimmat yksittäiset arvot (alle 2 me) saatiin tälläkin alueella muokkauskerroksesta olevista näytteistä. Saadut arvot ovat kuitenkin yleensä korkeampia kuin MÄKITIEN ja VIRRIN (1965) Keravan seudulta olevista näytteistä saamat tulokset. Heinosen (1956) analysoimien savinäytteiden keskiarvo ja Lohjan seudun muokkauskerroksen näytteiden keskiarvot vastaavat hyvin toisiaan. 
Taulukko 2. $\mathrm{N}$ ammoniumasetaattiin vaihtuvat $\mathrm{Ca}, \mathrm{Mg}$ ja $\mathrm{K}$ sekä vaihtokapasiteetti. Keskiarvoja standardipoikkeamin.

Table 2. Ca, Mg and $K$ exchangeable in $N$ ammonium acetate, and total exchange capacity. Mean values with standard deviations.

\begin{tabular}{lccccc}
\hline $\begin{array}{l}\text { Alue } \\
\text { Area }\end{array}$ & $\mathrm{Ca}$ & $\mathrm{Mg}$ & $\mathrm{K}$ & $\mathrm{CEC}$ \\
\cline { 2 - 3 } $\begin{array}{l}\text { Kerros } \\
\text { Depth }\end{array}$ & $\mathrm{me} / 100 \mathrm{~g}$ & $\mathrm{me} / 100 \mathrm{~g}$ & $\begin{array}{c}\% \text { of } \\
\mathrm{CEC}\end{array}$ & $\mathrm{me} / 100 \mathrm{~g}$ & $\mathrm{me} / 100 \mathrm{~g}$ \\
\hline
\end{tabular}

Muokkauskerros

Plough layer $0-20 \mathrm{~cm}$

$\begin{array}{lrrrrrr}\text { Lohja } \ldots \ldots \ldots \ldots \ldots \ldots \ldots \ldots \ldots \ldots \ldots \ldots . & 13.1 \pm 1.7 & 4.9 \pm 1.1 & 20 & 0.48 \pm 0.06 & 25 \pm 3 \\ \text { Vammala } \ldots \ldots \ldots \ldots \ldots \ldots \ldots \ldots \ldots \ldots \ldots . & 7.0 \pm 0.6 & 3.2 \pm 1.4 & 15 & 0.53 \pm 0.26 & 21 \pm 2\end{array}$

Jankko

Subsurface $20-40 \mathrm{~cm}$

\begin{tabular}{|c|c|c|c|c|c|}
\hline Lohja ................................. & $11.0 \pm 1.6$ & $7.5 \pm 1.6$ & 32 & $0.35 \pm 0.05$ & $23 \pm 3$ \\
\hline Vammala ................................... & $7.1 \pm 1.8$ & $5.4 \pm 1.4$ & 30 & $0.31 \pm 0.10$ & $18 \pm 3$ \\
\hline \multicolumn{6}{|l|}{$\begin{array}{l}\text { Pohjamaa } \\
\text { Subsoil } 40-60 \mathrm{~cm}\end{array}$} \\
\hline Lohja ............ & $11.5 \pm 1.6$ & $9.0 \pm 1.6$ & 37 & $0.40 \pm 0.07$ & $24 \pm 3$ \\
\hline Vammala .............................. & $8.5 \pm 0.9$ & $7.7 \pm 1.4$ & 35 & $0.45 \pm 0.10$ & $22 \pm 2$ \\
\hline
\end{tabular}

\section{Maan lajitekoostumus, orgaaninen hiili ja vaihtuva magnesium}

Lohjan alueen eri kerrosten keskimääräiset savespitoisuudet vaihtelevat välillä 50-56\% (taulukko 1). Vastaavat keskiarvot Vammalan alueella olivat $38-48 \%$. Molemmilla alueilla savespitoisuus on korkein pohjamaassa ja alin muokkauskerroksessa. Hienoa hiesua, jonka raekoko on kahdesta kuuteen mikrometriin, on keskimäärin $17-28 \%$. Savespitoisuuden ja vaihtuvan magnesiumin todettiin olevan positiivisessa korrelaatiossa Lohjan alueen kaikissa kerroksissa. Vammalan alueen näytteissä vain jankkokerroksessa on korrelaatio merkitsevä (taulukkc 3).

Hienohiesupitoisuuden ja vaihtuvan magnesiumin välinen korrelaatio on tässä aineistossa yleensä selvästi negatiivinen. Siten saveksen ja vaihtuvan magnesiumin riippuvuus on hyvin ilmeinen, minkä seikan mm. KAILA (1973) on todennut.

Tutkittujen muokkauskerrosnäytteiden orgaanisen hiilen keskimäärät ovat kummallakin tutkitulla alueella hyvin samanlaiset. Osa jankko- ja pohjamaakerrosten näytteistä voidaan luokittaa liejuisiksi saviksi, osa liejusaviksi. Käytetyn alue- ja kerrosryhmittelyn puitteissa saatiin vaihtuvan magnesiumin ja humuspitoisuuden välille yleensä negatiivinen korrelaatio (taulukko 3). Tähän vaikuttanee magnesiumionin heikko pidättyminen humukseen (HEINONEN 1956).

\section{Vuihtuvan magnesiumin suhde muihin vaihtuviin kationeihin}

Vaihtuvaa kalsiumia on näytteissä keskimäärin 7.0-13.1 me/100 g (taulukko 2). Lohjan seudun näytteissä pitoisuus on keskimäärin korkeampi kuin 
Taulukko 3. Magnesiumin korrelaatio orgaanisen hiilen sekä savi- ja hiesulajitteiden kanssa. Table 3. Correlation of exchangeable magnesium with organic carbon and with contents of clay and finer silt.

\begin{tabular}{|c|c|c|c|}
\hline $\begin{array}{l}\text { Alue } \\
\text { Area } \\
\text { Kerros } \\
\text { Depth }\end{array}$ & Org. C & $\begin{array}{c}\text { Saves } \\
\text { Clay }<2 \mu\end{array}$ & $\begin{array}{c}\text { Hieno hiesu } \\
\text { Finer silt } 2-6 \mu\end{array}$ \\
\hline \multicolumn{4}{|l|}{ Muokkauskerros - Plough layer $0-20 \mathrm{~cm}$} \\
\hline Lohja ......................................... & 0.10 & $0.70 * * *$ & $-0.42^{*}$ \\
\hline 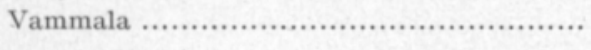 & $-0.84^{* *}$ & 0.13 & 0.47 \\
\hline \multicolumn{4}{|l|}{ Jankko - Subsurface $20-40 \mathrm{~cm}$} \\
\hline Lohja .............................................. & -0.17 & $0.78^{* * *}$ & $-0.49 * *$ \\
\hline Vammala ............................................... & 0.08 & $0.82^{* * *}$ & $-0.87 * * *$ \\
\hline \multicolumn{4}{|l|}{ Pohjamaa - Subsoil $40-60 \mathrm{~cm}$} \\
\hline Lohja ............................................... & $-0.37 *$ & $0.75 * * *$ & $-0.47 * *$ \\
\hline Vammala .......................................... & $-0.52^{*}$ & 0.30 & $-0.49^{\circ}$ \\
\hline
\end{tabular}

Vammalan näytteissä. Kerrosten väliset erot ovat vähäisiä. Kalsiumin ja magnesiumin ekvivalenttimäärien suhde on muokkauskerroksessa keskimäärin $2.2-2.6$ ja syvemmällä $1.1-1.5$. Suhde on Lohjan seudulla korkeampi kuin Vammalan seudulla.

Kalsiumin ja magnesiumin määrien välinen korrelaatio oli Lohjan seudun näytteissä positiivinen. Vammalan seudun näytteissä vastaava suhde oli merkitsevä vain jankkokerroksessa. Muckkauskerroksessa, johon lannoitus ja maanparannus vaikuttanevat voimakkaimmin, ja jonka lajitekoostumus oli karkein, korrelaatio oli heikoin (taulukko 4).

Taulukko 4. Vaihtuvien kationimäärien (me/100 g) väliset suhteet ja korrelaatiot.

Table 4. Ratios and correlations between the quantities (me/100 g) of the exchangeable cations.

\begin{tabular}{|c|c|c|c|c|}
\hline \multirow{4}{*}{$\begin{array}{l}\text { Alue } \\
\text { Area } \\
\text { Kerros } \\
\text { Depth }\end{array}$} & \multicolumn{2}{|c|}{$\mathrm{Ca} / \mathrm{Mg}$} & \multicolumn{2}{|c|}{$\mathrm{Mg} / \mathrm{K}$} \\
\hline & & & & \\
\hline & Suhde & Korrelaatio & Suhde & Korrelaatio \\
\hline & Ratio & Correlation & Ratio & Correlation \\
\hline \multicolumn{5}{|l|}{ Muokkauskerros - Plough layer $0-20 \mathrm{~cm}$} \\
\hline Lohja .............. & 2.6 & $0.62 * * *$ & 10 & -0.11 \\
\hline 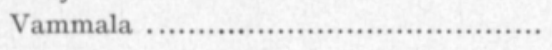 & 2.2 & 0.27 & 6 & $-0.67^{\circ}$ \\
\hline \multicolumn{5}{|l|}{ Jankko - Subsurface $20-40 \mathrm{~cm}$} \\
\hline Lohja ....................................... & 1.5 & $0.91 * * *$ & 21 & $0.52 * *$ \\
\hline 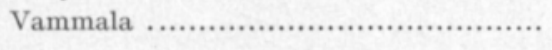 & 1.3 & $0.86 * * *$ & 18 & $0.66^{*}$ \\
\hline \multicolumn{5}{|l|}{ Pohjamaa - Subsoil $40-60 \mathrm{~cm}$} \\
\hline 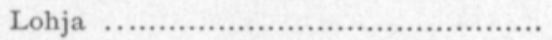 & 1.3 & $0.80 * * *$ & 23 & $0.52 * * *$ \\
\hline Vammala ...................................... & 1.1 & 0.20 & 17 & 0.34 \\
\hline
\end{tabular}


Vaihtuvaa kaliumia oli näytteissä keskimäärin eri kerroksissa $0.31-0.53$ me/100 g. Magnesiumin ja kaliumin ekvivalenttimäärien suhde vaihteli $6-23$ ilmaistuna eri kerrosten keskiarvoina. Vaihtuvan magnesiumin ja kaliumin välisellä korrelaatiolla oli muokkauskerroksesª otettujen näytteiden ryhmissä negatiivinen suunta, syvemmältä otettujen näytteiden ryhmissä oli korrelaatio sensijaan positiivinen. Muokkauskerroksen näytteiden erilainen magnesiumin ja kaliumin välinen korrelaatio syvempiin näytteisiin verrattuna saattaa johtua kalilannoituksesta ja se viittaa siihen mahdollisuuteen, jonka mm. HaHLin (1973) on todennut, että kalilannoitus lisää magnesiumin huuhtoutumista.

\section{Emäskyllästysaste}

Lohjan näytteiden keskimääräinen emäskyllästysaste on $82-95 \%$. Vammalan näytteiden vastaavat keskiarvot ovat $59-88 \%$. Keskimääräinen vaihtokapasiteetti on likimain sama eri kerroksissa (taulukko 2). Alueiden e1ot ovat suuremmat kuin kerrosten väliset erot. Lohjan näytteiden arvot ovat korkeampia johtuen luultavimmin korkeasta savespitoisuudesta.

Magnesiumin osuus vaihtokapasiteetista eli magnesiumkyllästysaste on Lohjan alueella keskımäärin $20-37 \%$ ja Vammalan alueella $15-35 \%$, ollen muokkauskerroksessa alhaisin ja pohjamaassa korkein (taulukko 2). Yksittäisten näytteiden emäskyllästysasteet olivat muokkauskerroksessa $11-36 \%$, jankkokerroksessa $7-42 \%$ ja pohjamaassa $12-49 \%$. Samansuuntaisen tuloksen ovat MÄKITIE ja VIRRI (1965) saaneet tutkiessaan Keravan seudun savia. ERviö ja MäKıтıE (1969) ovat saaneet savimaiden muokkauskerroksen magnesiumkyllästysasteeksi Hyvinkään-Nastolan alueella keskimäärin $15-24 \%$.

Heinosen (1956) käsityksen mukaan kasvien magnesiumin saannin kannalta ovat magnesiumin määrää ratkaisevasti tärkeämpiä sen osuus vaihtokapasiteetista ja sen suhde muihin kationeihin. Puutetta ilmenee todennäköisesti, kun magnesiumin osuus vaihtokapasiteetista on alle $6 \%$. Tämän tutkimuksen tulosten mukaan näyttää vaihtuvaa magnesiumia olevan Lohjan ja Vammalan alueiden savipelloissa yleensä viljelyyn riittävästi.

\section{Yhteenveto}

Lounaisen Suomen viljeltyjen savimaiden maanäytteistä määritettiin neutraaliammoniumasetaattiin vaihtuvia kationeja, joista tässä tarkastellaan magnesiumia ja sen suhdetta kalsiumiin ja kaliumiin.

Lohjan alueella, joka on Lounais-Suomen savialuetta, vaihtuvaa magnesiumia oli keskimäärin 4.9-9.0 milliekvivalenttia sadassa grammassa ilmakuivaa maata. Vammalan alueella, joka on savi- ja hiesualueiden rajalla, vastaavat keskiarvot olivat $3.2-7.7$ me. Alimmat keskiarvot saatiin muokkauskerroksesta $(0-20 \mathrm{~cm})$, korkeimmat pohjamaasta $(40-60 \mathrm{~cm})$. Näytteiden savespitoisuuden ja vaihtuvan magnesiumin määrien todettiin olevan positiivisessa korrelaatiossa, hiesupitoisuuden vastaavasti yleensä negatiivi- 
sessa samoinkuin melko suppealla alueella vaihtelevan humuspitoisuuden. Kalsiumin ja magnesiumin ekvivalenttimäärien suhteiksi saatiin muokkauskerroksessa 2.2-2.6, syvemmällä 1.1-1.5 sekä magnesiumin ja kaliumin suhteeksi $6-10$ ja $17-23$.

Vaihtuvaa magnesiumia näyttää tutkituissa savimaissa olevan kasvituotannon kannalta riittävästi ja suhteessa muihin kationeihin runsaasti.

\section{KIRJALLISUUTTA}

Brown, I. C. 1943. A rapid method of determining exchangeable hydrogen and total exchangeable bases of soils. Soil Sci. 56: $353-357$.

ERviö, R. \& MйкıтіE, O. 1969. Studies on the effect of clay and organic matter contents on the determination of cation exchange properties in clay soils by the ammonium acetate and methylene-blue methods. J. Scient. Agric. Soc. Finl. 41: 73-81.

HAHцrN, M. 1973. Kaliumgödslingseffekterna i relation till K/Mg-kvoten i växt och jord. Rapp. avd. växtnäringsl., Kungl. Lantbr. Högskolan, Uppsala. 69 p.

Heinonen, R. 1956. Magnesiumin tarpeesta Suomen pelloissa. Summary: Magnesium requirements in Finnish agriculture. Agrogeol. Publ. 65: 1-32.

KAILA, A. 1973. Calcium, magnesium and potassium in mineral soils from the southern half of Finland. Selostus: Suomen eteläpuoliskon kivennäismaitten kalsiumista, magnesiumista ja kaliumista. J. Scient. Agric. Soc. Finl. 45: 254-261.

MÄKITIE, O. \& VIRRI, K. 1965. On the exchange charasteristics of some clay soils in the Middle Uusimaa. Selostus: Keski-Uusimaan savimaiden kationinvaihto-ominaisuuksista. Ann. Agric. Fenn. 4: 277-289.

Schollenberger, C. J. \& Simon, R. H. 1945. Determination of exchangeable bases in soil, ammonium acetate method. Soil Sci. 59: 13-24.

SippolA, J. 1974. Mineral composition and its relation to texture and to some chemical properties in Finnish subsoils. Ann. Agric. Fenn. 13: 169-234.

VIRri, K. 1971. Lohja-Vihti. Summary: Soil map of Lohja-Vihti. Ann. Agric. Fenn. 10, Suppl. 1: $1-48+12$ soil maps.

- - 1973. Vammala-Mouhijärvi. Summary: Soil map of Vammala-Mouhijärvi. Ann. Agric. Fenn. 12, Suppl. 1: $1-45+12$ soil maps.

Käsikirjoitus saapunut 23.6.1976 